\title{
The effect of soluble- and insoluble-fibre supplementation on post-prandial glucose tolerance, insulin and gastric inhibitory polypeptide secretion in healthy subjects
}

\author{
BY L. M. MORGAN, J. A. TREDGER, J. WRIGHT AND V. MARKS \\ Department of Biochemistry, University of Surrey, Guildford GU2 $5 X H$, Surrey
}

(Received 31 July 1989 - Accepted 4 January 1990)

\begin{abstract}
Six healthy non-obese male subjects were given three test meals containing $100 \mathrm{~g}$ carbohydrate and $1.5 \mathrm{~g}$ soluble paracetamol, supplemented on one occasion with $10 \mathrm{~g}$ guar gum and on another with $10 \mathrm{~g}$ sugarbeet fibre. A further six subjects were given the same test meal supplemented on one occasion with $10 \mathrm{~g}$ soya-bean-cotyledon fibre and on another, $5 \mathrm{~g}$ glucomannan. Venous blood samples were taken before, and at intervals for 180 min following the meal, and analysed for insulin, gastric inhibitory polypeptide (GIP) and paracetamol (as an index of gastric emptying). Arterialized blood samples were taken and analysed for glucose. Meal supplementation with both guar gum and sugar-beet fibre improved glucose tolerance, but circulating glucose levels were unaffected by the addition of either soya-bean-cotyledon fibre or glucomannan to the meals. Supplementation with guar gum and glucomannan lowered postprandial insulin levels. Insulin levels were enhanced by addition of soya-bean-cotyledon fibre to the meal and unaffected by sugar-beet fibre. Post-prandial GIP levels were lowered in the guar-gum-supplemented meal and augmented with sugar-beet fibre supplementation. Addition of glucomannan and soya-beancotyledon fibre did not affect circulating GIP levels. The study failed to confirm previous reports of improved glucose tolerance following glucomannan and soya-bean-cotyledon fibre supplementation. The failure of sugar-beet fibre to reduce post-prandial insulin secretion despite improved glucose tolerance may be due to the observed increased secretion of GIP. The increased insulin levels seen following soyabean-cotyledon fibre supplementation cannot be attributed either to changes in glucose tolerance, GIP secretion or gastric emptying.
\end{abstract}

Dietary fibre: Insulin: Gastric inhibitory polypeptide: Glucose tolerance

The addition of various types of dietary fibre (Trowell, 1972) to oral carbohydrate loads has been shown to lower post-prandial circulating glucose levels in healthy human subjects. Soluble fibres, or non-starch polysaccharides, such as guar gum, a galactomannan derived from the seeds of the Indian cluster bean (Cyamopsis tetragonoloba), have been shown to be particularly effective (Leeds et al. 1975) and guar gum has been used clinically to improve metabolic control in patients with diabetes mellitus (Jenkins et al. 1977a; Morgan, 1985).

Other soluble polysaccharides such as glucomannan and pectin have also been reported to improve glucose tolerance under certain conditions (Jenkins et al. 1977b, 1984; Doi et al. 1981). In addition, some preparations of soya-bean-cotyledon fibre (SCF), a mixture of insoluble polysaccharides consisting mainly of arabinogalactan and arabinan (Aspinall et al. 1967), have been reported to reduce post-prandial reactive hypoglycaemia (Tsai et al. 1983) and improve glucose tolerance (Schweizer et al. 1983). Similar effects in diabetics have been reported with sugar-beet fibre (SBF), and a mixture of soluble (pectin) and insoluble polysaccharides (Hagandar, 1987; Hagandar et al. 1987). The clinical use of each of these various types of dietary fibres in the management of diabetes has been suggested at one time or another. 
Whilst the literature concerning the metabolic effects of guar gum is considerable it is comparatively scanty regarding other types of fibre. Previous studies have concentrated on the effect of fibre supplementation on the response to liquid test meals which are unrepresentative of the normal diet; there has been little investigation into the mechanisms whereby any effect that was produced was achieved. Guar gum has been shown to decrease post-prandial secretion of the insulinotropic gastrointestinal hormone gastric inhibitory polypeptide (GIP) and this may be the main mechanism by which it lowers post-prandial insulin secretion (Morgan et al. 1979).

Gastric emptying rates can also affect glucose tolerance and whilst the effect of guar gum on gastric emptying has been investigated (Rainbird et al. 1982; Tredger et al. 1984; Rainbird \& Low, 1986) and shown not materially to change it, little is known about the effects of other types of dietary fibre. The present study was designed to compare the effect on glucose tolerance and insulin secretion in healthy human subjects of four non-starch polysaccharides, namely guar gum (galactomannan), Konjac (glucomannan), SCF and SBF, when mixed into a high-carbohydrate solid-liquid test breakfast. Gastric emptying rates were monitored by the addition of soluble paracetamol to the meal and measuring post-prandial plasma levels of the drug. This has previously been shown to be a useful marker of liquid-phase gastric emptying (Holt et al. 1979; Morgan et al. 1988). Postprandial GIP levels were also monitored.

\section{MATERIALS AND METHODS}

\section{Clinical studies}

Twelve healthy male volunteers participated in the study. Their mean age was $19 \cdot 5$ (sD 9.0) years and body mass index 22.9 (SD $3 \cdot 1) \mathrm{kg} / \mathrm{m}^{2}$. Each subject gave his informed consent, and the study was approved by the Ethical Committees of St Luke's Hospital, Guildford, and of the University of Surrey. Subjects attended the Clinical Investigation Unit on three separate occasions after an overnight fast at least 1 week apart.

\section{Expt A. Guar gum and SBF supplementation}

Six of the subjects were given three test meals in random order containing $100 \mathrm{~g}$ carbohydrate, which on one occasion included $10 \mathrm{~g}$ guar gum (Guarem; Rybar Laboratories, Amersham, Bucks) and on another, $10 \mathrm{~g} \mathrm{SBF}$ (Beta Fibre; British Sugar plc, Peterborough) as detailed in Table 1. Each type of dietary fibre was mixed with the honey before being eaten. Soluble paracetamol (Soluble Panadol; Wynpharm, Guildford), $1.5 \mathrm{~g}$ dissolved in $150 \mathrm{ml}$ water, was consumed simultaneously with the meal on each occasion and plasma paracetamol levels were measured as an index of liquid gastric emptying.

\section{Expt B. Glucomannan and SCF supplementation}

Six of the subjects were given the test meal (Table 1) in random order either with or without $10 \mathrm{~g} \mathrm{SCF}$ (Fibrim; Ralston Purina Co., St. Louis, USA) or $5 \mathrm{~g}$ glucomannan (Tsuruta Food Engineering Co., Gunma-Ken, Japan). Paracetamol (1.5 g) was taken with the meal as in the previous experiment.

Venous blood samples were collected through an indwelling venous cannula inserted into an antecubital vein and kept patent with $0 \cdot 123 \mathrm{M}$-sodium citrate. Samples were collected whilst the subjects were fasting at rest and at frequent timed intervals for $180 \mathrm{~min}$ from the start of the meals.

Arterialized blood samples were collected at similar time intervals from an indwelling cannula inserted into a dorsal vein of the contralateral hand, heated to approximately $55^{\circ}$ by means of an electric heating blanket. 
Table 1. Composition of the control meal, consumed by subjects with and without fibre supplementation

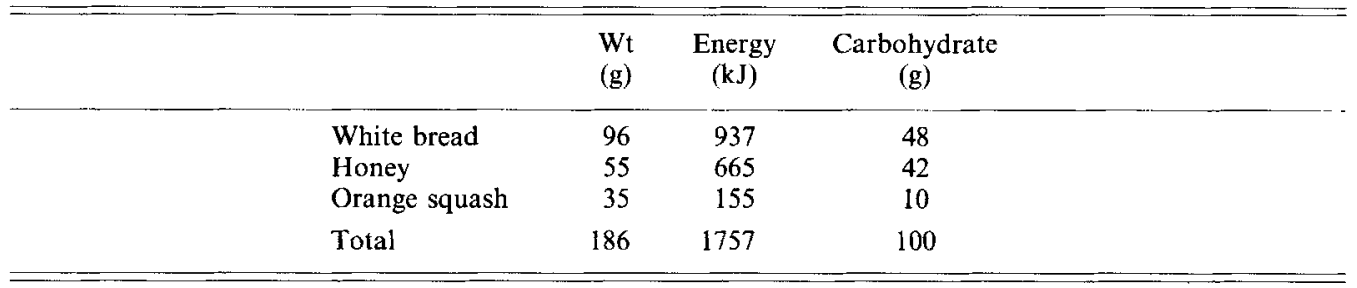

\section{Chemical analyses}

Plasma glucose concentrations were measured in the arterialized and venous blood samples using an automated glucose oxidase (EC 1.1.3.4) technique on a Cobas Bio centrifugal analyser. Measurement of plasma immunoreactive insulin and GIP concentrations were performed on venous blood by double-antibody techniques (Morgan et al. 1978) using antisera supplied by Guildhay Antisera Ltd (Guildford). The sensitivity of the insulin assay was $2.5 \mathrm{mU} / 1$ and of the GIP assay $110 \mathrm{ng} / 1$; interassay coefficients of variation were $7 \cdot 4$ and $11 \%$ respectively. Plasma paracetamol was measured by an automated enzymic technique (Hallworth, 1983).

\section{Statistical analyses}

Results were compared using one-way analysis of variance, followed by Duncan's multiple-range analysis and repeated measures design ANOVA, where appropriate. Differences at individual time-points between control and fibre-supplemented meals were compared using Student's test for paired data. Areas under the curve (AUC) were calculated using the trapezoidal rule. Values of $P<0.05$ were accepted as statistically significant.

\section{RESULTS}

Meals containing the various dietary fibres under test were well-tolerated by the subjects, although their acceptability was reduced. This was mainly because fibre supplementation caused changes in the taste and consistency of the honey. The SCF was the least preferred as it had a sawdust-like consistency and a gritty texture. No adverse side effects were experienced by any of the subjects.

\section{Expt A. Guar gum and SBF supplementation}

Analysis of variance demonstrated a significant effect of fibre supplementation on the postprandial glucose, insulin and GIP curves in comparison with the unsupplemented control meal $(P<0.05)$. Supplementation with either guar gum or SBF improved glucose tolerance (peak mean arterialized plasma glucose level $9.55($ SE 0.44$) \mathrm{mmol} / 1$ for control meal $v .7 .26$ (SE 0.39) mmol/1 for guar-gum-supplemented meal $(P<0.01)$ and 8.07 (SE 0.56) mmol/l for SBF-supplemented meal $(P<0.025)$ ) (see Fig. 1). The AUC for glucose $(0-90 \mathrm{~min})$ was also significantly reduced with both guar gum $(P<0.02)$ and SBF $(P<0.05)$ supplementation (see Table 2).

Post-prandial peripheral insulin levels were reduced with guar gum supplementation (mean peak plasma insulin level 103 (SE 192) $\mathrm{mU} / 1$ for control v. 61 (SE 8.0) mU/1 for guar gum $(P<0 \cdot 01))$. The AUC for insulin $(0-90 \mathrm{~min})$ was also significantly reduced $(P<0 \cdot 02)$ by guar gum (Fig. 2). Insulin levels were unaffected by the addition of SBF to the meal. 

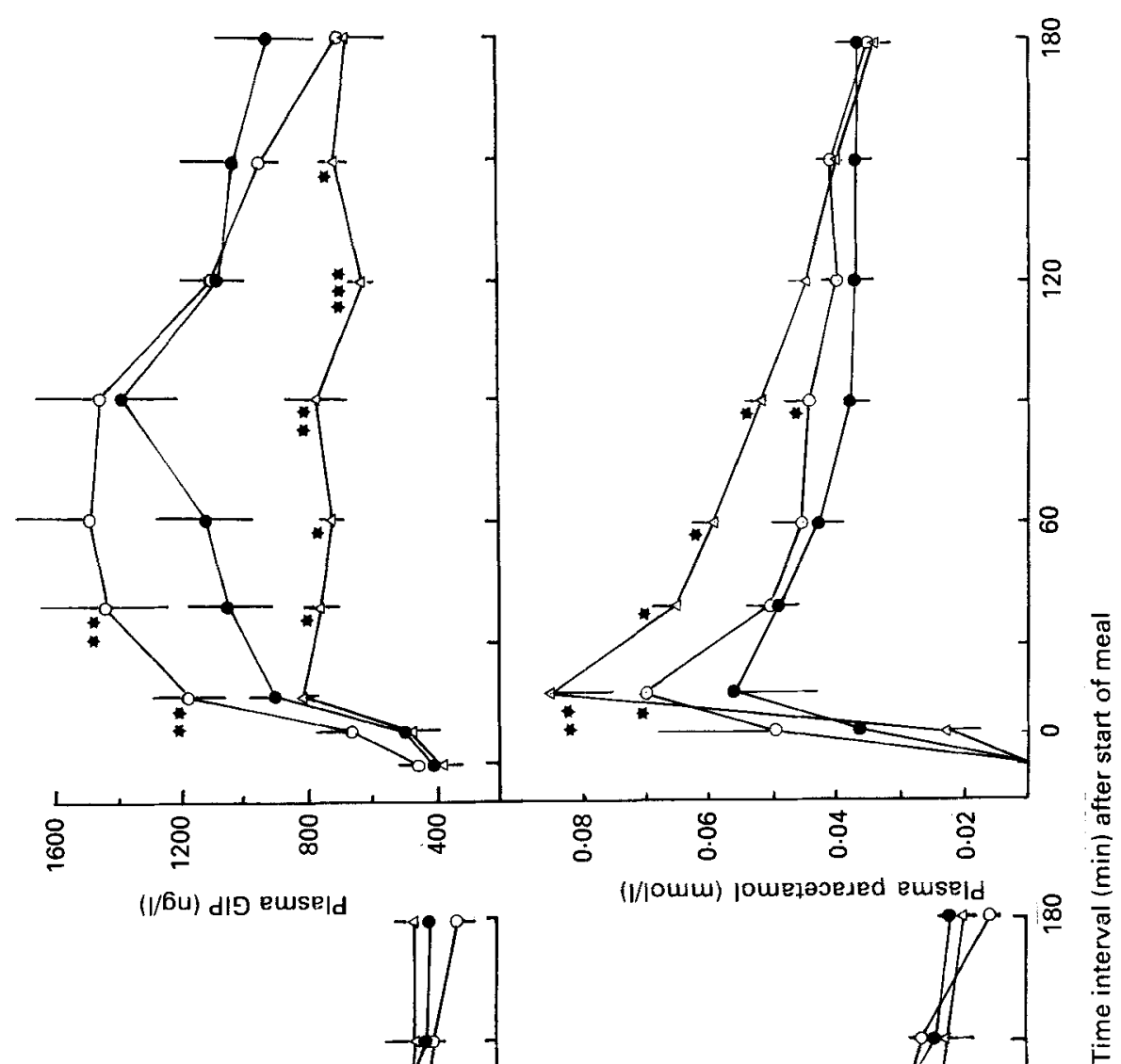

蛋

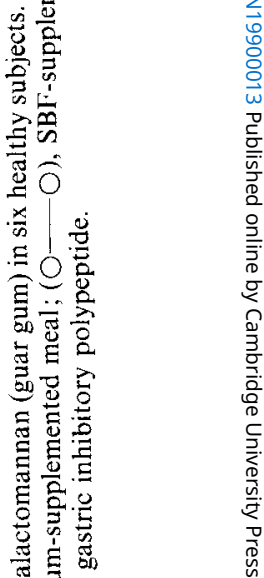

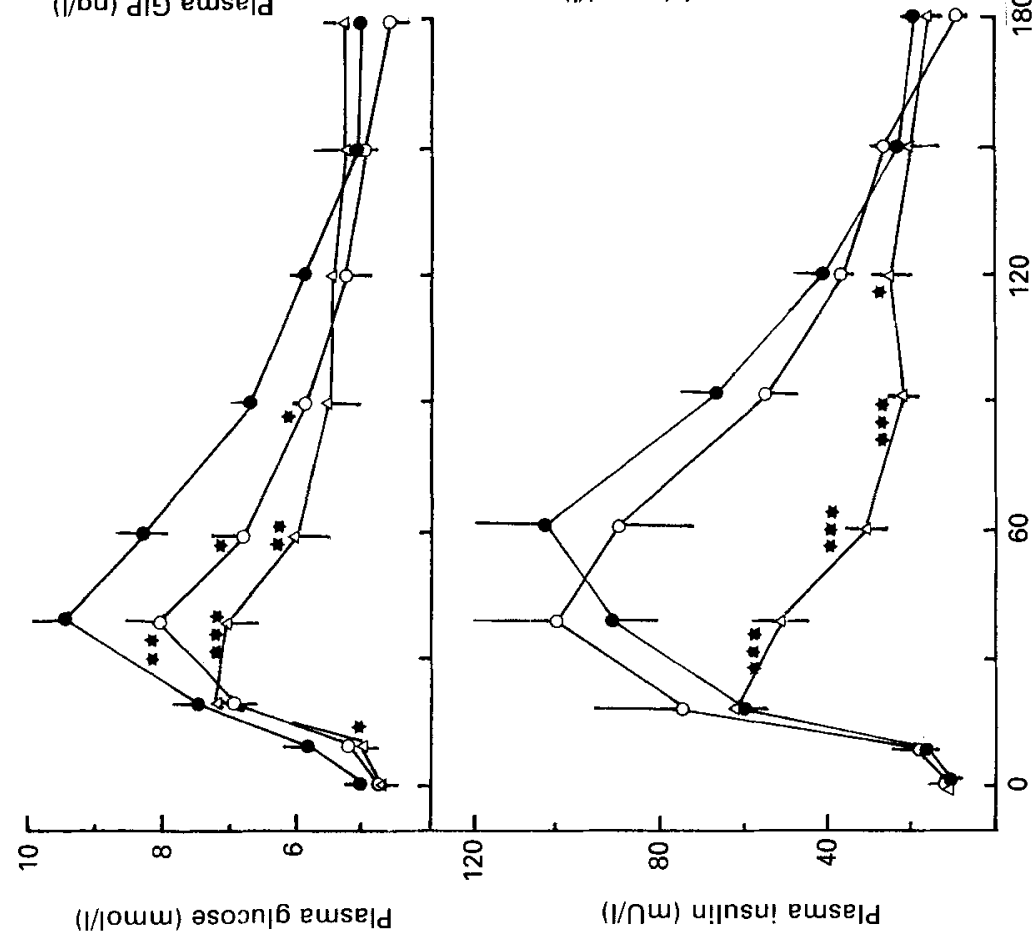

of 10

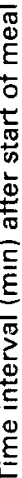

을

5 50

$\frac{1}{\infty}<$

2

递范

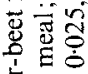

䆑方 $v$

कि है

$00^{*}$

कीㅇํㅇ

氖|

焉

可的

풍

空

흠ㅎㅁ

of

8 离

क 는

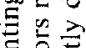

氖

옹

के

踏

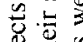

我焉

$<$

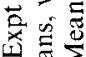

- 压.

엘 
Table 2. Incremental plasma glucose, insulin and gastric inhibitory polypeptide $(G I P)$ responses $(0-90 \mathrm{~min})$ in six healthy subjects following a test meal containing $100 \mathrm{~g}$ carbohydrate with and without fibre supplementation

(Mean values with their standard errors)

\begin{tabular}{|c|c|c|c|c|c|c|c|c|}
\hline & \multicolumn{2}{|c|}{$\begin{array}{c}\text { Glucose } \\
(\mathrm{mmol} / 1 . \mathrm{min})\end{array}$} & \multicolumn{2}{|c|}{$\begin{array}{l}\text { Insulin } \\
\text { (mU/1.min) }\end{array}$} & \multicolumn{2}{|c|}{$\begin{array}{c}\text { GIP } \\
(\mu \mathrm{g} / 1 . \mathrm{min})\end{array}$} & \multicolumn{2}{|c|}{$\begin{array}{c}\text { Paracetamol } \\
(\mathrm{mmol} / 1 \mathrm{~min})\end{array}$} \\
\hline & Mean & SE & Mean & $\mathrm{SE}$ & Mean & SE & Mean & $\mathrm{SE}$ \\
\hline \multicolumn{9}{|l|}{ Expt A } \\
\hline Control meal & 690 & 23 & 6528 & 978 & 919 & 115 & 5260 & 1210 \\
\hline Guar gum $(10 \mathrm{~g})$ & 557 & $38^{* *}$ & 3279 & $392^{* *}$ & 647 & $41^{*}$ & 8058 & 950 \\
\hline $\begin{array}{l}\text { Sugar-beet } \\
\text { fibre }(10 \mathrm{~g})\end{array}$ & 589 & $33^{*}$ & 6502 & 1095 & 1138 & $162^{*}$ & 7208 & 1480 \\
\hline \multicolumn{9}{|l|}{ Expt $\mathbf{B}$} \\
\hline Control meal & 687 & 41 & 5989 & 456 & 1297 & 173 & 6748 & 1063 \\
\hline Glucomannan (5 g) & 710 & 47 & 4911 & $547^{* *}$ & 1210 & 205 & 5593 & 735 \\
\hline $\begin{array}{l}\text { Soya-bean-cotyledon } \\
\text { fibre }(10 \mathrm{~g})\end{array}$ & 663 & 26 & 7102 & $550^{* *}$ & 1125 & 158 & 7391 & 1193 \\
\hline
\end{tabular}

Mean values were significantly different from those for the control meal : ${ }^{*} P<0-05, * * P<0.02$.
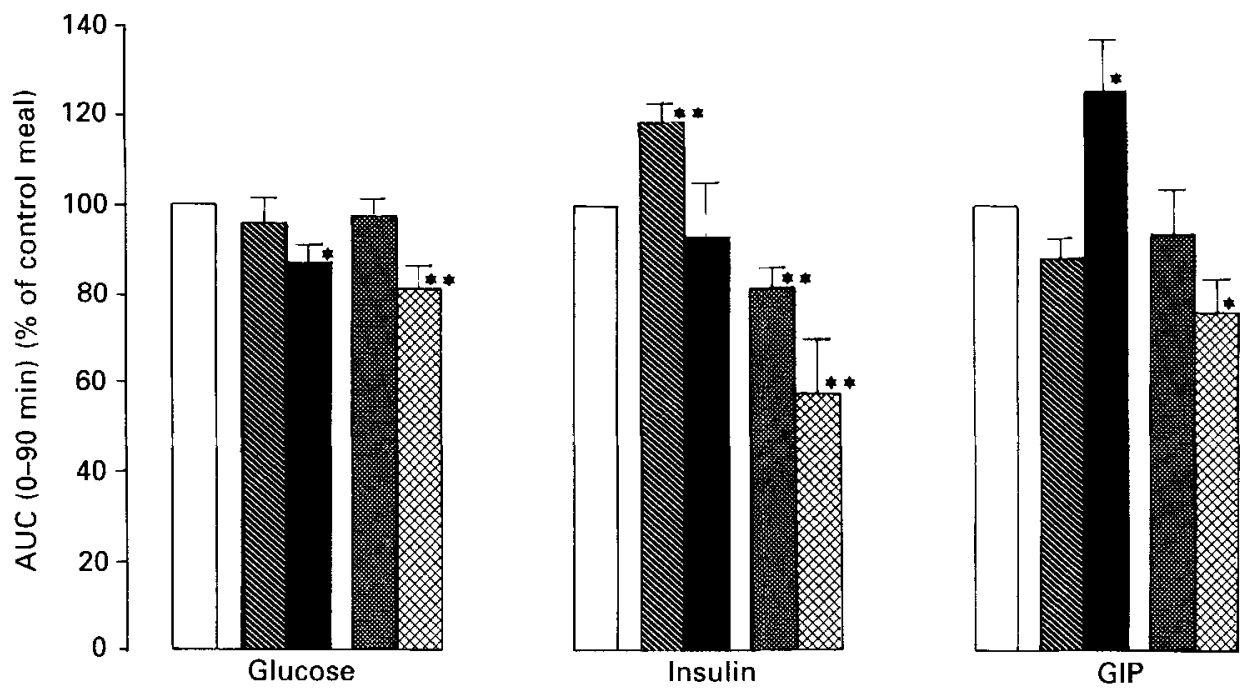

Fig. 2. Expts A and B. Effects of supplementing a $100 \mathrm{~g}$ carbohydrate meal with $10 \mathrm{~g}$ soya-bean-cotyledon fibre (SCF), $10 \mathrm{~g}$ sugar-beet fibre (SBF), $10 \mathrm{~g}$ galactomannan (guar gum) or $5 \mathrm{~g}$ glucomannan (Konjac) on integrated post-prandial insulin, glucose and gastric inhibitory polypeptide (GIP) responses in six healthy subjects. Values are means, with their standard errors represented by vertical bars, expressed as a percentage of the control (fibre-

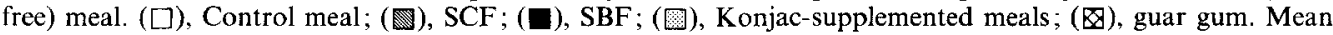
values were significantly different from control values: ${ }^{*} P<0.05,{ }^{* *} P<0.02$, AUC, area under curve.

Post-prandial GIP levels were affected by both guar gum and SBF. Peak GIP levels were significantly lowered by guar gum supplementation (mean peak GIP level after control meal 1390 (SE 214) ng/l; after guar-gum-supplemented meal 893 (SE 54) ng/1 $(P<0.025)$ ). The integrated GIP response 0-90 min following the meal was also significantly decreased $(P<0.05)$ by guar gum.

Following SBF supplementation plasma GIP levels were significantly higher $(P<0 \cdot 025)$ at 20 and $40 \mathrm{~min}$ (see Fig. 1). The integrated GIP response was also significantly increased $(P<0.05)$ with SBF. 
Plasma paracetamol levels were significantly higher between 20 and $90 \mathrm{~min}$ following the guar-gum-supplemented meal compared with the control $(P<0.05)$, and also following the SBF-supplemented meal at 20 and $90 \mathrm{~min}(P<0.05)$ (Fig. 1). However, the incremental areas $(0-90 \mathrm{~min})$ under the paracetamol curves were not significantly different for either fibre-supplemented meal (Table 2).

\section{Expt B. Glucomannan and SCF supplementation}

Analysis of variance demonstrated a significant post-prandial effect of glucomannan and SCF supplementation on the post-prandial insulin curves alone in comparison with the unsupplemented control meal $(P<0 \cdot 05)$. Glucomannan supplementation resulted in significantly reduced peak insulin levels $(96.2$ (SE 11) $\mathrm{mU} / 1$ v. 64.3 (SE 2.6) $\mathrm{mU} / 1$ for control and glucomannan meals respectively, $P<0.02)$. The incremental area $(0-90 \mathrm{~min})$ under the insulin curve was significantly reduced $(P<0.02)$ by glucomannan, but significantly increased $(P<0.02)$ by addition of SCF to the meal (Fig. 2). Mean peak post-prandial insulin levels were also higher following addition of SCF to the meal, but not significantly so. (Mean peak insulin 104 (SE 6.7) $\mathrm{mU} / \mathrm{I}$ v. 119 (SE 14) $\mathrm{mU} / 1$ for control and SCF supplemented meals respectively, $P>0.05$.)

Post-prandial glucose, GIP and paracetamol levels were not affected by addition of either glucomannan or SCF to the control meal.

\section{DISCUSSION}

The four types of dietary fibre studied were chosen because they had each previously been reported to reduce the rise in circulating glucose levels following their addition either to an oral liquid glucose load or to a test meal in normal subjects or diabetics. In the present study, we found that only guar gum and SBF were effective in reducing the rise in blood glucose levels produced by our mixed solid-liquid high-carbohydrate test meal. SCF, which has been reported to reduce post-prandial reactive hypoglycaemia, and to improve glucose tolerance in hyperlipidaemic patients with impaired glucose tolerance given glucose in solution (Tsai et al. 1983, 1987), had no effect under the more physiological conditions of a test meal. However, the effects of SCF on glucose levels previously reported were relatively minor (Tsai et al. 1987) and may have depended on the type of SCF preparation used (Schweizer et al. 1983) as well as on its mode of administration.

Glucomannan has been claimed to be more effective than guar gum in improving glucose tolerance (Doi et al. 1981) on a weight-for-weight basis. We limited the amount of glucomannan added to our test meal to $5 \mathrm{~g}$ because of a previous report that the incorporation of more than $5.2 \mathrm{~g}$ glucomannan into a meal can cause abdominal pain and diarrhoea (Doi et al. 1981). We were not, therefore, able to make a direct comparison between the glucomannan-supplemented meal with the meal supplemented with $10 \mathrm{~g}$ guar gum. We were unable to confirm previous reports which described an effect of $3.9 \mathrm{~g}$ and of $2.6 \mathrm{~g}$ glucomannan on glucose tolerance in normal subjects (Doi et al. 1979, 1981). However, one of the earlier studies used a test meal of unspecified composition and the other investigated the effect of $2.6 \mathrm{~g}$ glucomannan on the effects produced by a $50 \mathrm{~g}$ glucose load given in liquid form, so once again direct comparisons cannot be made.

Whereas both guar gum and glucomannan supplementation reduced post-prandial circulating insulin levels, SBF supplementation did not in spite of its ability to improve glucose tolerance. A possible explanation of this failure of SBF supplementation to reduce the plasma insulin response to the meal may lie in the post-prandial GIP levels obtained. Guar gum supplementation diminished post-prandial GIP secretion, in response to 
ingestion of the meal, in agreement with previous studies (Morgan et al. 1979, 1985). GIP secretion was actually increased by the addition of SBF to the meal. This augmentation may have been sufficient to maintain the level of insulin secretion despite a smaller rise in the prevailing (arterial) blood glucose levels.

Although post-prandial insulin levels were attenuated by glucomannan and increased by SCF, these were not associated with any changes in post-prandial glucose or GIP levels or gross changes in liquid gastric emptying rates. Other mechanisms must therefore be responsible for the changes observed. These could include changes in glucose absorption, insulin sensitivity or the relation between hepatic portal and peripheral venous insulin levels as a result of fibre ingestion. High plasma 'enteroglucagon' concentrations have also been observed following the ingestion of some high-viscous-fibre diets (Jenkins et al. 1984), possibly reflecting a rise in glucagon-like polypeptide-1 (GLP-1 (7-36)), a recently isolated insulinotropic polypeptide which is at least as effective as GIP in stimulating insulin release (Kreymann et al. 1987). The effects of fibre supplementation on GLP-1 secretion are unknown, and its contribution to post-prandial insulin secretion must therefore remain speculative.

In the present study liquid gastric emptying, as assessed by circulating paracetamol levels, appeared slightly accelerated both by guar gum and by SBF supplementation. Previous reports using test meals of varying compositions have suggested that gastric emptying rates remain unaltered (Rainbird et al. 1982; Tredger et al. 1984) or are delayed (Wilmshurst \& Crawley, 1980) by guar gum supplementation. The composition of the meal is clearly of importance in determining the extent and way that fibre supplementation affects gastric emptying and caution should, therefore, be exercised before extrapolating findings obtained under one set of experimental conditions to other situations. The findings presented illustrate both the complexity and diversity of mechanisms governing the improvement in glucose tolerance produced by dietary fibre supplementation. Non-starch polysaccharides such as glucomannan and guar gum (galactomannan), though structurally similar and with the ability to form highly viscous solutions, seemingly have diverse effects on gut hormone secretion, gastric emptying and glucose tolerance.

The effects on glucose tolerance observed for a test meal of a particular composition cannot necessarily be extrapolated to other situations. Studies on the effects of fibre supplementation following a single test meal are necessary to elucidate their mechanism of action and are an indication of their usefulness in a clinical situation. However, long-term supplementation studies where the fibre in question is incorporated into a variety of different meals which form part or all of a subject's habitual diet are also necessary. This is especially relevant in diabetics where measurement of glycated proteins in blood provides a more reliable index of clinical efficacy of dietary fibre supplementation taken over a prolonged period of time than do measurements of fasting or even post-prandial blood glucose levels.

The authors wish to thank British Sugar plc, Rybar Laboratories, Britannia Pharmaceuticals and Dr P. Ellis for supplying sugar beet fibre, Guarem, Fibrium and Konjac respectively. They also thank British Sugar plc for financial support.

\section{REFERENCES}

Aspinall, G. O., Begbie, R. \& McKay, J. E. (1967). Polysaccharide components of soybeans. Cereal Science Today 12, 224-226.

Doi, K., Matsuura, M., Kawara, A. \& Baba, S. (1979). Treatment of diabetics with glucomannan (konjac mannan). Lancet $\mathbf{i}, 987$.

Doi, K., Matsuura, M., Kawara, A., Ama, R. U. \& Baba, S. (1981). Effect of glucomannan (konjac powder) on 
glucose and lipid metabolism in normal and diabetic subjects. In Proceedings of the Third Symposium on Diabetes Mellitus in Asia \& Oceana, pp. 306-312 [J. S. Melish, J. Hanna and S. Baba, editors]. Amsterdam: Elsevier.

Hagandar, B. (1987). Fibre and the diabetic diet. Acta Medica Scandinavica 716, 1-55.

Hagandar, B., Asp, N. G., Efendic, S., Nilsson-Ehle, P., Lundquist, I. \& Schersten, B. (1987). Beet fibre in the diet. Scandinavian Journal of Gastroenterology 22, Suppl. 129, 284.

Hallworth, M. J. (1983). Enzymic method for acetaminophen adapted to a centrifugal analyser. Clinical Chemistry 29, 2123 -2124 .

Holt, S., Heading, R. C., Carter, D. C., Prescott, L. F. \& Tothill, P. (1979). Effect of gel fibre on gastric emptying and absorption of glucose and paracetamol. Lancet i, 636 639 .

Jenkins, D. J. A., Leeds, A. R., Gassull, M. A., Cochet, B. \& Alberti, K. G. M. M. (1977b). Decrease in postprandial insulin and glucose concentrations by guar and pectin. Annals of Internal Medicine 86, 20-23.

Jenkins, D. J. A., Thorne, M. J. \& Taylor, R. H. (1984). Slowly digested carbohydrate food improves impaired carbohydrate tolerance in patients with cirrhosis. Clinical Science 66, 649 657.

Jenkins, D. J. A., Wolever, T. M. S., Hockaday, T. D. R., Leeds, A. R., Howarth, R., Bacon, S., Apling, E. C. \& Dilawari, J. (1977a). Treatment of diabetes with guar gum. Lancet ii, 779-780.

Kreymann, B., Williams, G., Ghatei, M. A. \& Bloom, S. R. (1987). Glucagon-like peptide-1 7-36: a physiological incretin in man. Lancet ii, 1300-1304.

Leeds, A. R., Gassull, M. A., Metz, G. L. \& Jenkins, D. J. A. (1975). Food: influence of form on absorption. Lancet $\mathbf{i i}, 1213$.

Morgan, L. M. (1985). Use of guar in the treatment of diabetics. In Diabetes 1985, pp. 831-835 [M. Serrano-Rios and P. J. Lefebvre, editors]. Amsterdam: Elsevier.

Morgan, L. M., Goulder, T. J., Tsiolakis, D., Marks, V. \& Alberti, K. G. M. M. (1979). The effect of unabsorbable carbohydrate on gut hormones. Diabetologia 17, 85-89.

Morgan, L, M., Morris, B. A. \& Marks, V. (1978). Radioimmunoassay of gastric inhibitory polypeptide. Annals of Clinical Biochemistry 15, 172-177.

Morgan, L. M., Tredger, J. A., Hampton, S. M., French, A. P., Peake, J. C. F. \& Marks, V. (1988). The effect of dietary modification and hyperglycaemia on gastric emptying and gastric inhibitory polypeptide (GIP) secretion. British Journal of Nutrition 60, 29-37.

Morgan, L. M., Tredger, J. A., Madden, A., Kwasowski, P. \& Marks, V. (1985). The effect of guar-gum on carbohydrate, fat and protein stimulated gut hormone secretion. British Journal of Nutrition 53, 467-475.

Rainbird, A. L. \& Low, A. G. (1986). Effect of guar gum on gastric emptying in growing pigs. British Journal of Nutrition 55, 87-98.

Rainbird, A. L., Low, A. G. \& Sambrook, I. E. (1982). Lack of effect of guar gum on gastric emptying in pigs. Proceedings of the Nutrition Society 39, 42A.

Schweizer, T. F., Bekhechi, A. R., Koellreutter, B., Reimann, S., Pometta, D. \& Bron, B. A. (1983). Metabolic effects of dietary fibre from dehulled soybeans in humans. American Journal of Clinical Nutrition $38,1-11$.

Tredger, J. A., Morgan, L. M., Peake, J. \& Marks, V. (1984). Effect of guar gum on the rate of gastric emptying in human subjects. Regulatory Peptides 9, 350.

Trowell, H. C. (1972). Ischaemic heart disease and dietary fibre. American Journal of Clinical Nutrition 25, $926-932$.

Tsai, A. C., Mott, E. L., Owen, G. M., Bennick, M. R., Lo, G. S. \& Steinke, F. H. (1983). Effects of soy polysaccharide on gastro-intestinal functions, nutrient balance, steroid excretions, glucose tolerance, serum lipids and other parameters in humans. American Journal of Clinical Nutrition 38, 504-511.

Tsai, A. C., Vinik, A. I., Lusichak, A. \& Lo, G. S. (1987). Effects of soy polysaccharide on post-prandial plasma glucose, insulin, glucagon, pancreatic polypeptide, somatostatin and triglyceride in obese diabetic patients. American Journal of Clinical Nutrition 45, 596-601.

Wilmshurst, P. \& Crawley, J. C. W. (1980). The measurement of gastric transit time in obese subjects using ${ }^{24} \mathrm{Na}$ and the effects of energy content and guar gum on gastric emptying and satiety. British Journal of Nutrition 44, $1-6$. 